\title{
Volume of Material Removal on Distortion in Machining Thin Wall Thin Floor Components
}

\author{
Garimella Sridhar, Ramesh Babu Poosa
}

Department of Mechanical Engineering, University College of Engineering, Osmania University, Hyderabad, India

Email address:

garimella_s@yahoo.com (G. Sridhar),prbmechou@yahoo.com (R. B. Poosa)

\section{To cite this article:}

Garimella Sridhar, Ramesh Babu Poosa. Volume of Material Removal on Distortion in Machining Thin Wall Thin Floor Components. International Journal of Mechanical Engineering and Applications. Vol. 3, No. 5, 2015, pp. 86-93. doi: 10.11648/j.ijmea.20150305.12

\begin{abstract}
Thin wall thin floor monolithic components produced from prismatic blocks are machined on CNC machines by removing material up to $95 \%$. Components distort because of stresses induced due to severe heat generated and plastic deformation during cutting. Distortion of the components after machining aluminium alloys is major problem faced in aerospace and automobile industries. The volume of the material removed has direct bearing on machining time, which may lead to distortion. The objective of this study is to determine the effect of volume of material removal on the distortion of aluminium 2014 T651 alloy machined from prismatic block. Machining experiments were carried out with 5 different blank sizes to produce a representative component with same machining parameters. Distortion is measured on the face opposite to the machined surface and maximum deviations were used for comparisons between distortion and volume of material removal.
\end{abstract}

Keywords: Volume of Material Removal, Distortion, Blank Size

\section{Introduction}

With high strength to weight ratios and reduced assembly costs, sheet metal and multiple part assemblies are replaced by single piece monolith high strength aluminium alloy designs. With huge amount of material to be removed from large areas machining of these on $\mathrm{CNC}$ machines has become quite common and inevitable. Previous studies of authors on challenges in machining these components show that one of the biggest problems is distortion [1]. In a general manufacturing scenario all the monolithic thin structured components are produced on $\mathrm{CNC}$ machining centres from Pre-machined Prismatic blanks of planned sizes and thickness. The blanks are generally cut from rolled sheets of pre-planned thickness and are sized to the required dimensions on a conventional milling machine before machining them on $\mathrm{CNC}$ machining centres. As the volume of material removed is up to $95 \%$, the components distort due to stresses induced into the component because of temperature gradient and differential plastic deformations during cutting [2-4]. The magnitude, distribution and type of residual stresses induced during cutting is the main cause of distortion which is a function of machining parameters, tool geometry, cutting strategy and clamping methodology for a component of given material [5].

In recent years, lot of research was done to control the distortion of parts during machining. Hengbo Cui, Jong-Yun Jung and Dug-Hee Moon applied Taguchi method to know affect of deformation caused by heat during cutting of $\mathrm{AL}$ $7050 /$ T7451 and found that cutting speed is the most influencing factor which causes deformation due to heat and the change of feed range has an insignificant effect on heat deformation [6]. Dong, Hui-yue, and Ying-lin KE carried out comparison of simulation and machining experiments on wing spar made of aluminium 7075 alloy using single tool- tooth milling simulation using Deform 3D, importing the force and temperature data into Abacus and simulating the machining experiments further by restart calculation and local re-meshing. The experiments showed good agreement with the simulation results and demonstrated that this method can be used to select optimal tool-path and machining sequences for minimizing distortion [7]. J-F. Lalonde, M.A. Gharghouri and J-F. Chatelain in their experiments and measurement of residual stresses by neutron diffraction method on controlled pre-processed blanks and standard blanks found that, the standard aluminium blanks distorted more because of asymmetrical bulk residual stresses in the blank because of previous operations before machining [8]. Younger, Mandy S., and Kenneth H. Eckelmeyer in their study concluded that distortion increases with increasing residual stress magnitude, increasing machining depth, and increasing machining asymmetry [9]. Denkena, B., and L. de León conducted 
machining experiments and showed in the results that machining operation and cutting edge geometry has a definite influence in the residual depth profile and residual stress distribution which effect distortion [10]. Marusich T.D., DA. Stephenson, S. Usui, and S. Lankalapalli proposed a methodology for distortion in thin-walled components due to both bulk and machining induced residual stresses which will aid in selecting parameters which can minimize distortion [3]. O. Belgasim and M. H. El-Axir in their study on aluminium magnesium alloy using response surface method, conducted experiments and concluded that residual stresses are sensitive to tool nose radius and feed rate. Cutting speed and depth of cut are significant parameters affecting maximum residual stresses which in turn affects distortion [11]. Similar results were achieved by author in experiments conducted using taguchi method to know the effect of distortion in machining aluminium alloy AA2014 T651. Depth of cut and width of cut were found to be significant contributors in machining distortion [12]. Keleshian, N, et al., in their work conducted machining experiments on aluminium alloy 7249 and observed that solution treatment temperature, quenching media, and various machining sequences affect distortion [13] Chatelain, Jean-François, Jean-François Lalonde, and Antoine $\mathrm{S}$. Tahan conducted experiments on a thin representative part to compare distortions with and without existing residual stresses in work pieces and concluded that initial residual stresses embedded within raw material has an effect on the final part deformation [5]. Songtao Wang, Zheng Minli, Fan Yihang, and Li Zhe conducted machining experiments on aluminium alloy 7475-T7351 and concluded that machining deformation of thin-walled components can be effectively controlled with the parameter combination of big radial cutting depth and small axial cutting depth in the condition of high spindle speed [14]. Huang, Xiaoming, et al., conducted high speed milling experiments on aluminium alloy 7050-T7541, measured residual stresses on the surface \& subsurface of the work piece and showed that decrease of the cutting speed with increase of the feed rate lead to increase of compressive residual stresses [15]. Huang, Xiaoming, Jie Sun, and Jianfeng Li studied the effects of bulk residual stresses \& machining induced residual stresses and observed that machining induced residual stresses is the primary cause of the distortion and has greater effect when the thickness is below $1.25 \mathrm{~mm}$, also location of the part in the raw material has some effect on distortion [16].

Although, much research was done on distortion during machining of thin structured components, the impact of volume of material removal on distortion was not studied. Volume of material removed is total amount of material machined out from the prismatic blank to form component. As thickness of the blank increases the volume of the material to be removed and time of machining increases. This may lead to increase in influence of magnitude and distribution of residual stresses and distortion of the component after machining and removing from the fixture. So, in order to understand the effect of volume of material removal on distortion, machining experiments were carried on representative thin wall thin floor part from prismatic blocks of different thicknesses on CNC machining centre using aluminium alloy 2014 T651 under same machining conditions.

\section{Experimental Setup and Procedure}

In this study milling experiments were carried out on Vertical CNC machining centre on a representative thin wall thin floor part to know the effect of volume of material removal on distortion of the component.

\subsection{Workpiece}

Aluminium alloy 2014 T651 is used as work piece material. The mechanical properties of the material are shown in Table 1 and chemical properties of the material are shown in Table 2. The alloy is copper based aluminium alloy which is solution treated, artificially age hardened and stress relieved by stretching. This alloy is commonly used for airframes and mechanical packages for avionics. The blank sizes of length $105 \mathrm{~mm}$ and width $40 \mathrm{~mm}$ with different thicknesses i.e., 12 $\mathrm{mm}, 14 \mathrm{~mm}, 16 \mathrm{~mm}, 18 \mathrm{~mm}$, and $20 \mathrm{~mm}$ are used for the experiment. The representative thin wall thin floor component for experimental work is shown in Figure 1.

Table 1. Mechanical Properties.

\begin{tabular}{ll}
\hline Property & Value \\
\hline Yield strength & $380 \mathrm{Mpa}$ \\
Tensile strength & $405 \mathrm{Mpa}$ \\
Hardness Rockwell B & 82 \\
Density & $2.80 \mathrm{~g} / \mathrm{cc}$ \\
Poisson's Ratio & 0.2 \\
\hline
\end{tabular}

Table 2. Chemical composition.

\begin{tabular}{ll}
\hline Property & Value \\
\hline Copper & 3.8 to 4.8 \\
Magnesium & 0.2 to 0.8 \\
Silicon & 0.6 to 0.9 \\
Iron & 0.7 max \\
Manganese & 0.2 to 1.2 \\
Aluminium & Reminder \\
\hline
\end{tabular}
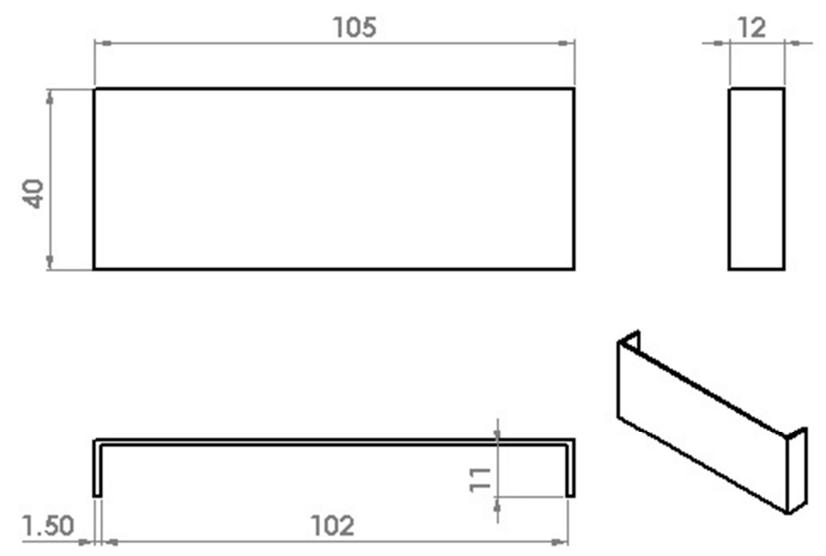

All Dimensions are in $\mathrm{mm}$

Figure 1. Experimental Workpiece. 


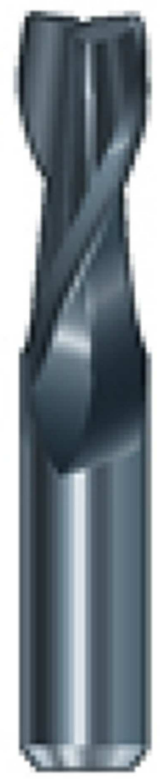

Figure 2. Solid Carbide slot Drill.

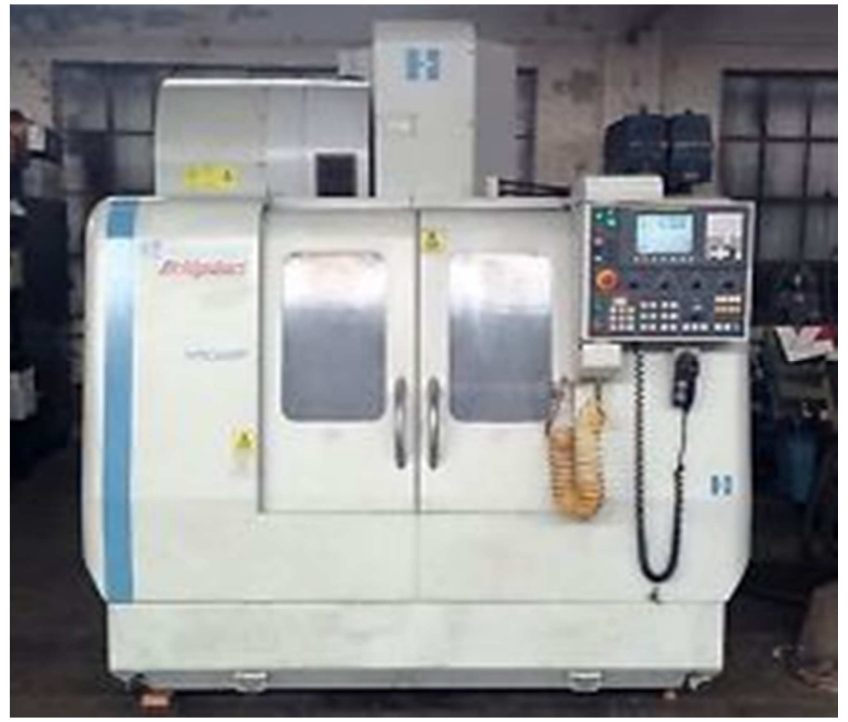

Figure 3. Hardinge Bridgeport VMC 600 P3.

Table 3. Specification of Machine.

\begin{tabular}{ll}
\hline Maximum RPM & $\mathbf{8 0 0 0}$ RPM \\
\hline No. of Axes & 3 -Axes \\
X Axis Travel & $600 \mathrm{~mm}$ \\
Y Axis Travel & $510 \mathrm{~mm}$ \\
Z Axis Travel & $510 \mathrm{~mm}$ \\
Rapid Traverse & $30 \mathrm{~m} / \mathrm{min}$ \\
Feed & $12 \mathrm{~m} / \mathrm{min}$ \\
Power & $13 \mathrm{~kW}$ \\
Tool Station & $20 \mathrm{Tools}$ \\
Maximum Load & $700 \mathrm{~kg}$ \\
\hline
\end{tabular}

\subsection{Tool}

All the machining experiments were carried out using low helix two flute solid carbide Slot Drill $\varnothing 10 \mathrm{~mm}$. Figure 2 shows the picture of the tool. New cutter is used for each machining experiment to eliminate the affect of tool wear. The machining experiments were carried out on Hardinge Bridgeport VMC 600 P3 3-axis Vertical Machining Centre as shown in Figure 3. Table 3 shows the specifications of the machine tool. All the experiments were carried by holding the component from the bottom using specially made vacuum fixture as shown in Figure 4.

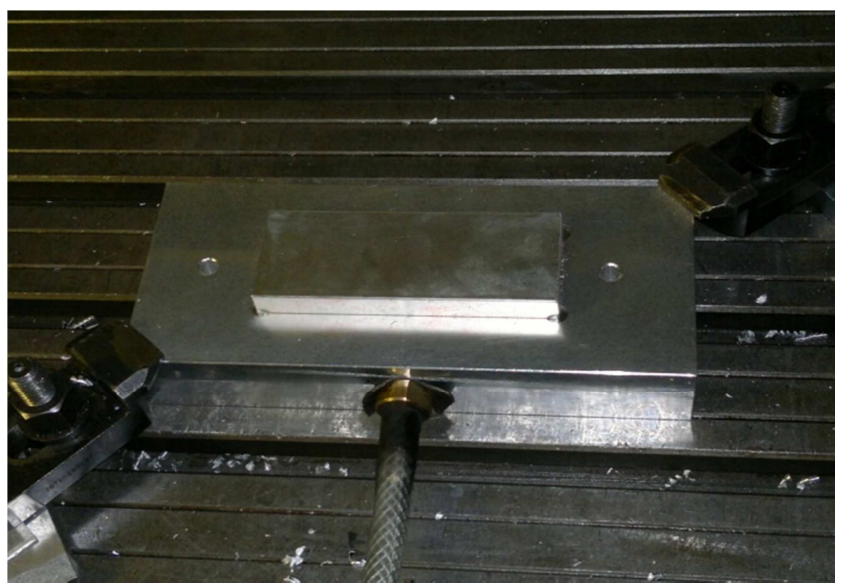

Figure 4. Vacuum Fixture along with work piece.

\subsection{Measurement}

Before Experiments, 18 points are marked on the opposite side of the face to be machined on all the work pieces as shown in Figure 5. The distortion is measured by taking the difference of Deviation before and after machining on the 18 marked places and maximum deviation is taken for comparison. Distortion measurements were carried using Metris LK Integra using CAMIO 4.4 software with Specifications: Size $800 \mathrm{~mm}$ X $700 \mathrm{~mm}$ X $600 \mathrm{~mm}$, Accuracy $1.9+\mathrm{L} / 450 \mu$, Repeatability $2.2 \mu$ and probe error $3.6 \mu$ as shown in Figure 6. Twist in the components was also measured using Feeler gauges. The measurement of twist is shown in Figure 7. Comparisons between the experiments were done by taking the maximum deviation of the work piece after machining.

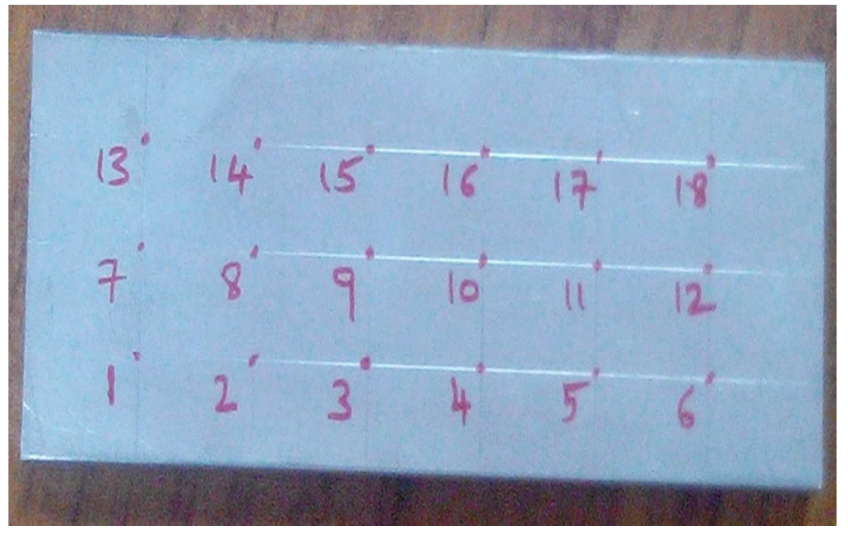

Figure 5. Marking of measuring point. 


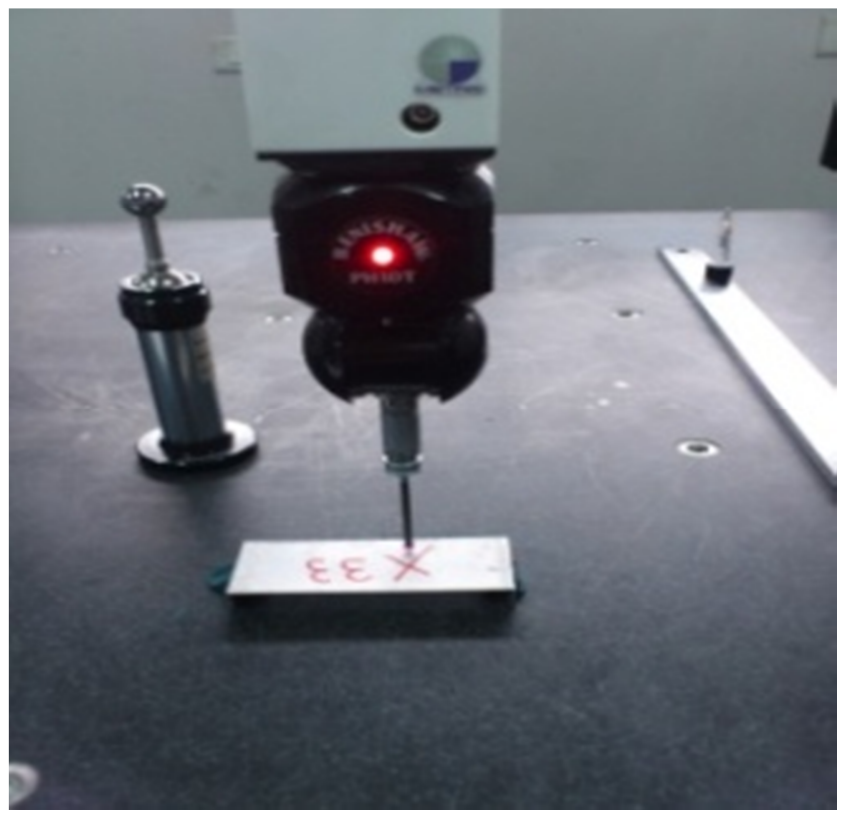

Figure 6. CMM with work piece.

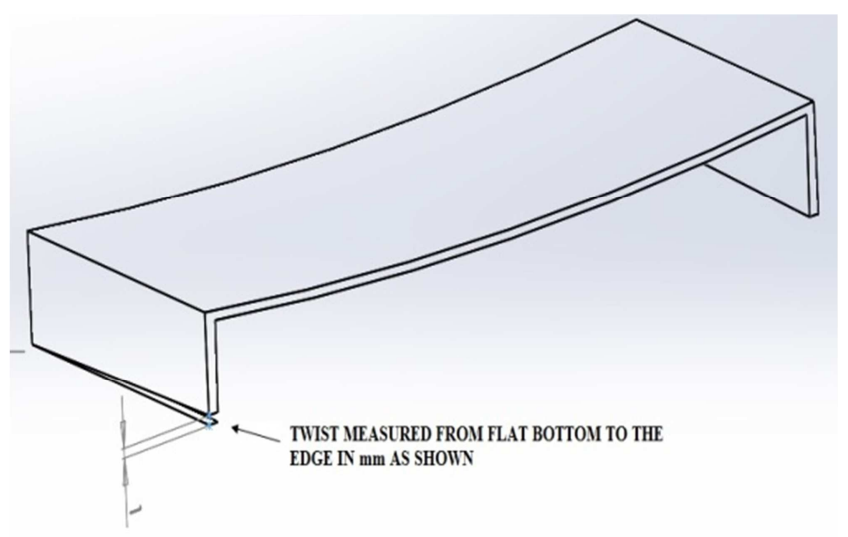

Figure 7. Picture showing measurement of twist.

Table 4. Machining Parameters.

\begin{tabular}{ll}
\hline Title & Value \\
\hline Feed & $0.1 \mathrm{~mm} /$ Tooth \\
Speed & $120 \mathrm{~m} / \mathrm{min}$ \\
Depth of cut & $1 \mathrm{~mm}$ \\
Width of cut & $7 \mathrm{~mm}$ \\
Coolant & Dry machining \\
\hline
\end{tabular}

\subsection{Methodology}

Aluminium rolled plates of $12 \mathrm{~mm}, 14 \mathrm{~mm}, 16 \mathrm{~mm}, 18$ $\mathrm{mm}$ and $20 \mathrm{~mm}$ thick were cut into sizes $110 \mathrm{~mm} \mathrm{X} 45 \mathrm{~mm}$. The blanks were then sized to $105 \mathrm{~mm} \mathrm{X} 40 \mathrm{~mm}$ on a vertical milling machine. After sizing, all the blanked were stress relieved, there by assuming very little or almost zero bulk residual stresses before machining them on $\mathrm{CNC}$ machining centre. The blanks after stress relief were machined by holding the part on specially made vacuum fixture from the bottom using low helix two flute solid carbide Slot Drill ø 10 $\mathrm{mm}$. The machining conditions used for milling all the blanks is shown in Table 4. All the machining experiments were carried out under same machining conditions.

Each blank during machining is taken out of fixture for every depth of cut which is $1 \mathrm{~mm}$ and measurements were taken for distortion and twist. The cutting strategy adopted for the experiments was pocket Inside out as shown in Figure 8. Three sample work pieces were machined for each thickness of blank.

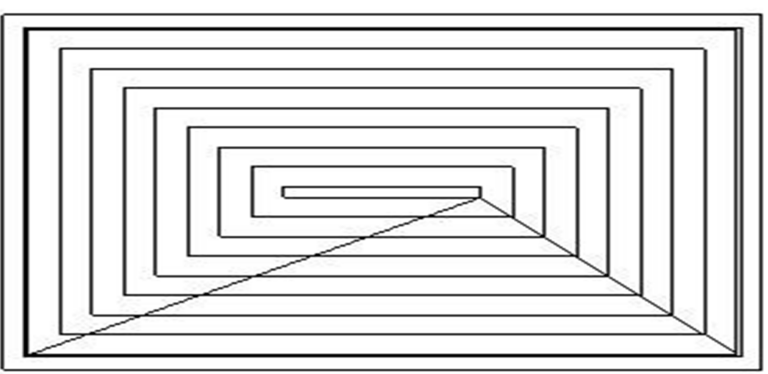

Figure 8. Tool Path Strategy pocket inside out.

\section{Experimental Results and Discussions}

Distortion and Twist measurements were taken for every $1 \mathrm{~mm}$ depth of machining for all the blanks. The distortion and twist measurements for blank thickness of $20 \mathrm{~mm}, 18$ $\mathrm{mm}, 16 \mathrm{~mm}, 14 \mathrm{~mm}$, and $12 \mathrm{~mm}$ for every $1 \mathrm{~mm}$ depth of cut are taken for 3 samples each and maximum distortion and twist were recorded for comparison. Table 5 shows the values of distortion and twist at every $1 \mathrm{~mm}$ depth of cut for blank thickness $20 \mathrm{~mm}$. The maximum distortion and twist values for the blanks of all thicknesses at every $1 \mathrm{~mm}$ depth of machining are shown in Table 6. Comparative values of distortion \& twist with respect to volume of material removed is shown in Table 7.

It can be observed from Table 6 that distortion and twist was observed for all the components machined. Significant distortion and twist was noticed only after the thickness of the components in the floor (bottom) is less than $3 \mathrm{~mm}$ after machining, for all the components. Figure 9 shows distortion and twist with respect to volume of material removal. It can be seen that, there no significant increase in distortion and twist with increase in volume of material removal.

The results clearly show that distortion of the components does not depend on the amount of material removed. As the amount of material machined increased from $44880 \mathrm{~mm}^{3}$ to $700800 \mathrm{~mm}^{3}$ there was no significant increase in distortion from initial distortion of $0.45 \mathrm{~mm}$ indicating that the distortion of the components may depend on machining parameters and tool parameters. The slight increase in twist for $20 \mathrm{~mm}$ thick blanks may be attributed to the variation of bulk residual stresses distribution existing in the blank prior to machining. It can be observed from Figure 10 and Figure 11 that the distortion and twist of the components was significant at thickness less than $3 \mathrm{~mm}$ for all the blanks indicating the effect of machining induced surface stresses causing distortion as reported in previous research $[5,15,16]$. 


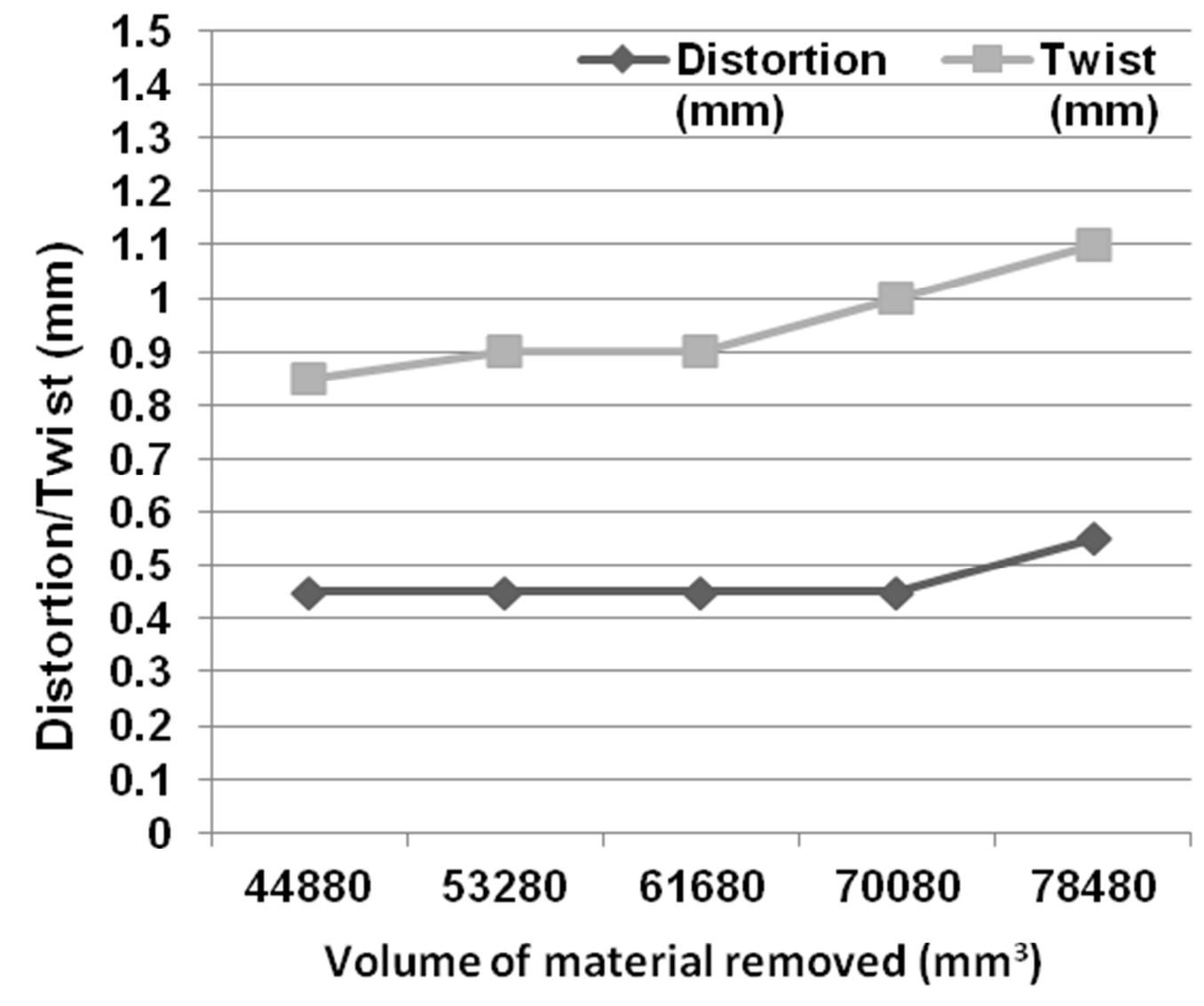

Figure 9. Comparison of distortion and twist.

Table 5. Distortion and Twist values for $20 \mathrm{~mm}$ Blank.

\begin{tabular}{|c|c|c|c|c|c|c|c|c|c|}
\hline \multirow{2}{*}{$\begin{array}{l}\text { Blank } \\
(\mathbf{m m})\end{array}$} & \multirow{2}{*}{$\begin{array}{l}\text { Distortion / Twist at } \\
\text { Thickness }\end{array}$} & \multicolumn{2}{|l|}{ Sample 1} & \multicolumn{2}{|l|}{ Sample2 } & \multicolumn{2}{|l|}{ Sample3 } & \multicolumn{2}{|l|}{ Maximum } \\
\hline & & Dist. (mm) & Twist (mm) & Dist. (mm) & Twist (mm) & Dist. (mm) & Twist (mm) & Dist. (mm) & Twist (mm) \\
\hline \multirow{20}{*}{20} & 20 & 0 & 0 & 0 & 0 & 0 & 0 & 0 & 0 \\
\hline & 19 & 0 & 0 & 0 & 0 & 0 & 0 & 0 & 0 \\
\hline & 18 & 0 & 0 & 0 & 0 & 0 & 0 & 0 & 0 \\
\hline & 17 & 0 & 0 & 0 & 0 & 0 & 0 & 0 & 0 \\
\hline & 16 & 0 & 0 & 0 & 0 & 0 & 0 & 0 & 0 \\
\hline & $15 \mathrm{~S}$ & 0 & 0 & 0 & 0 & 0 & 0 & 0 & 0 \\
\hline & 14 & 0 & 0 & 0 & 0 & 0 & 0 & 0 & 0 \\
\hline & 13 & 0 & 0 & 0 & 0 & 0 & 0 & 0 & 0 \\
\hline & 12 & 0 & 0 & 0 & 0 & 0 & 0 & 0 & 0 \\
\hline & 11 & 0 & 0 & 0 & 0 & 0 & 0 & 0 & 0 \\
\hline & 10 & 0 & 0 & 0 & 0 & 0 & 0 & 0 & 0 \\
\hline & 9 & 0 & 0 & 0 & 0 & 0 & 0 & 0 & 0 \\
\hline & 8 & 0 & 0 & 0 & 0 & 0 & 0 & 0 & 0 \\
\hline & 7 & 0 & 0 & 0 & 0 & 0 & 0 & 0 & 0 \\
\hline & 6 & 0 & 0 & 0 & 0 & 0 & 0 & 0 & 0 \\
\hline & 5 & 0 & 0 & 0 & 0 & 0 & 0 & 0 & 0 \\
\hline & 4 & 0.05 & 0.1 & 0.08 & 0.1 & 0.08 & 0.12 & 0.08 & 0.12 \\
\hline & 3 & 0.21 & 0.4 & 0.22 & 0.45 & 0.2 & 0.45 & 0.22 & 0.45 \\
\hline & 2 & 0.35 & 0.7 & 0.34 & 0.75 & 0.35 & 0.75 & 0.35 & 0.75 \\
\hline & 1 & 0.55 & 1.1 & 0.49 & 1.05 & 0.52 & 1.05 & 0.55 & 1.1 \\
\hline
\end{tabular}


Table 6. Maximum values of Distortion and Twist (mm) at various thicknesses.

\begin{tabular}{|c|c|c|c|c|c|c|c|c|c|c|c|c|c|c|c|c|c|c|c|c|c|}
\hline $\begin{array}{l}\text { Blank } \\
(\mathrm{mm})\end{array}$ & $\begin{array}{l}\text { Thick-ness } \\
\text { (mm) }\end{array}$ & 20 & 19 & 18 & 17 & 16 & 15 & 14 & 13 & 12 & 11 & 10 & 9 & 8 & 7 & 6 & 5 & 4 & 3 & 2 & 1 \\
\hline \multirow{2}{*}{20} & DIST. & 0 & 0 & 0 & 0 & 0 & 0 & 0 & 0 & 0 & 0 & 0 & 0 & 0 & 0 & 0 & 0 & 0.08 & 0.22 & 0.35 & 0.55 \\
\hline & TWIST & 0 & 0 & 0 & 0 & 0 & 0 & 0 & 0 & 0 & 0 & 0 & 0 & 0 & 0 & 0 & 0 & 0.12 & 0.45 & 0.75 & 1.1 \\
\hline \multirow{2}{*}{18} & DIST. & - & - & 0 & 0 & 0 & 0 & 0 & 0 & 0 & 0 & 0 & 0 & 0 & 0 & 0 & 0 & 0 & 0.05 & 0.33 & 0.45 \\
\hline & TWIST & - & - & 0 & 0 & 0 & 0 & 0 & 0 & 0 & 0 & 0 & 0 & 0 & 0 & 0 & 0 & 0 & 0.25 & 0.55 & 1 \\
\hline \multirow{2}{*}{16} & DIST. & - & - & - & - & 0 & 0 & 0 & 0 & 0 & 0 & 0 & 0 & 0 & 0 & 0 & 0 & 0 & 0.05 & 0.22 & 0.45 \\
\hline & TWIST & - & - & - & - & 0 & 0 & 0 & 0 & 0 & 0 & 0 & 0 & 0 & 0 & 0 & 0 & 0 & 0.25 & 0.6 & 0.9 \\
\hline \multirow{2}{*}{14} & DIST. & - & - & - & - & - & - & 0 & 0 & 0 & 0 & 0 & 0 & 0 & 0 & 0 & 0 & 0 & 0 & 0.25 & 0.45 \\
\hline & TWIST & - & - & - & - & - & - & 0 & 0 & 0 & 0 & 0 & 0 & 0 & 0 & 0 & 0 & 0 & 0.15 & 0.6 & 0.9 \\
\hline \multirow{2}{*}{12} & DIST. & - & - & - & - & - & - & - & - & 0 & 0 & 0 & 0 & 0 & 0 & 0 & 0 & 0 & 0.15 & 0.22 & 0.45 \\
\hline & TWIST & - & - & - & - & - & - & - & - & 0 & 0 & 0 & 0 & 0 & 0 & 0 & 0 & 0 & 0.15 & 0.44 & 0.85 \\
\hline
\end{tabular}

Table 7. Maximum values of Distortion and Twist with respect to material removal volume.

\begin{tabular}{|c|c|c|c|c|c|c|}
\hline Blank (mm) & Part Volume $\left(\mathrm{mm}^{3}\right)$ & Blank Volume $\left(\mathrm{mm}^{3}\right)$ & $\begin{array}{l}\text { Material removal } \\
\text { Volume }\left(\mathrm{mm}^{3}\right)\end{array}$ & \% Material Removed & Distortion (mm) & Twist (mm) \\
\hline 12 & 5520 & 50400 & 44880 & 89.10 & 0.45 & 0.85 \\
\hline 14 & 5520 & 58560 & 53040 & 90.60 & 0.45 & 0.9 \\
\hline 16 & 5520 & 66720 & 61200 & 91.80 & 0.45 & 0.9 \\
\hline 18 & 5520 & 74880 & 69360 & 92.70 & 0.45 & 1 \\
\hline 20 & 5520 & 83040 & 77520 & 93.40 & 0.55 & 1.1 \\
\hline
\end{tabular}

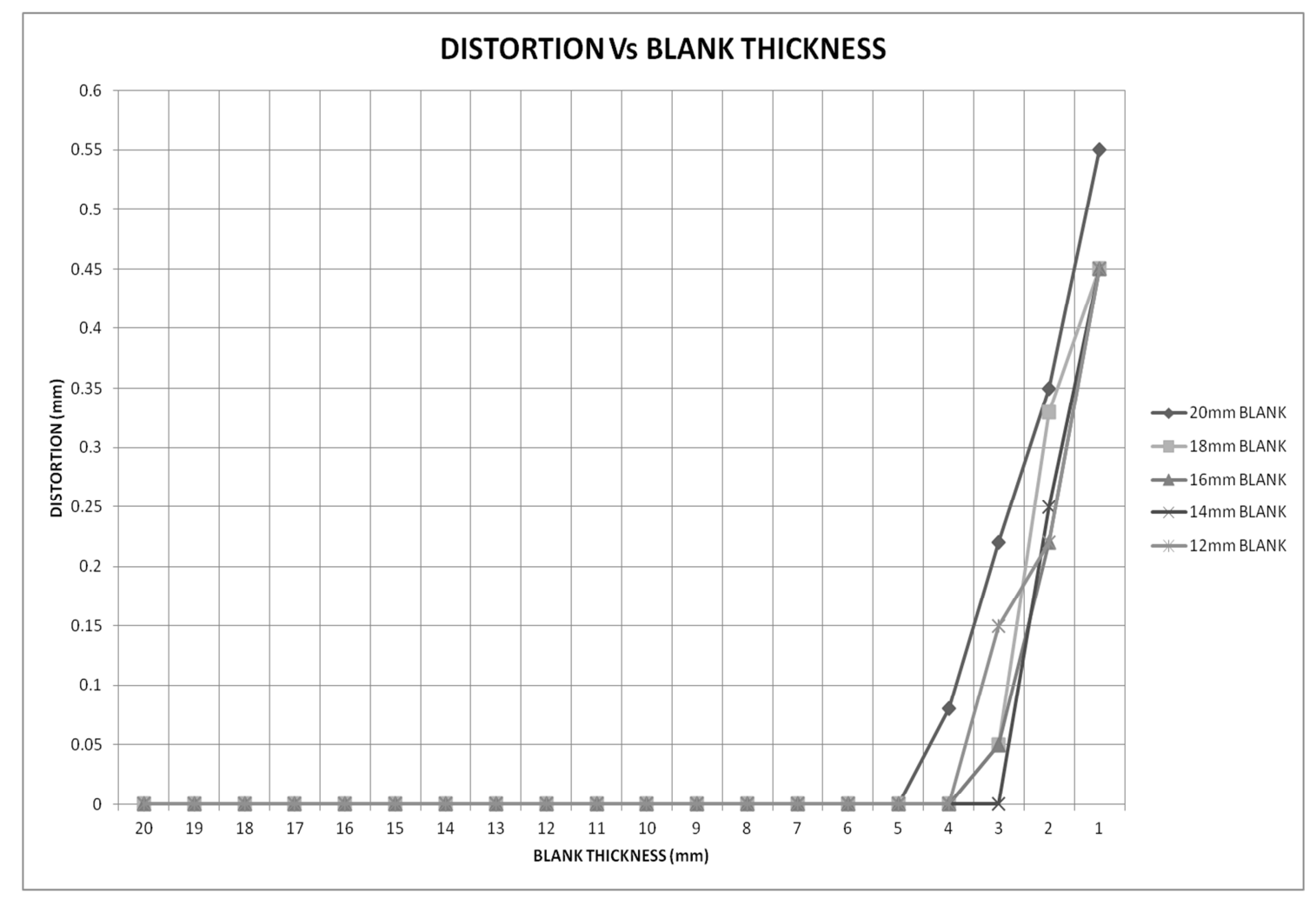

Figure 10. Values of Distortion at different thicknesses of blanks. 


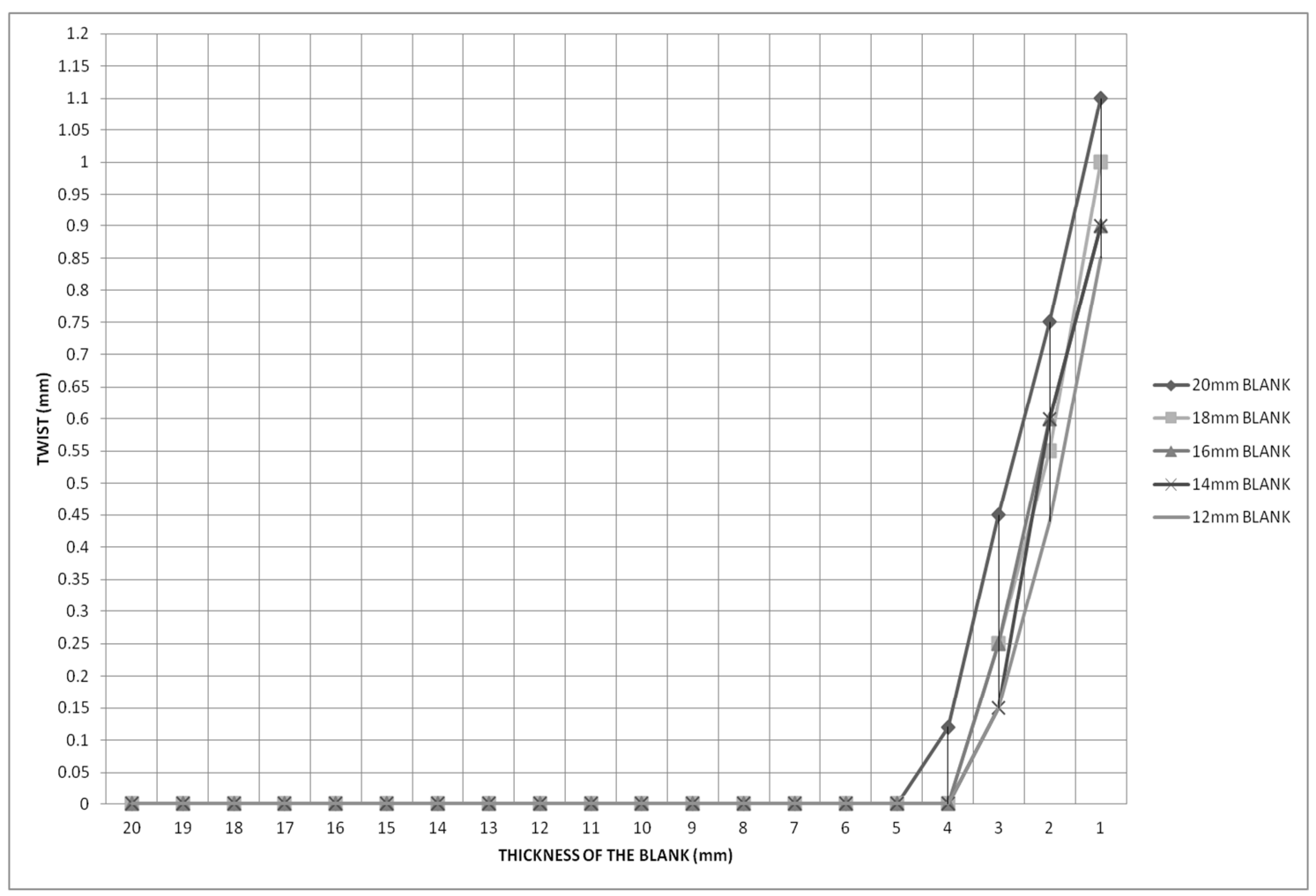

Figure 11. Values of Twist at different thicknesses of blanks.

\section{Conclusions}

A comparison of distortion and twist vis-a-vis material removal volume was done. Machining experiments were carried with constant machining process parameters on stress relieved aluminium alloy 2014 T651 with different thickness of blanks. It was found that the amount of material removal has no significant affect on distortion. Distortion may be due to process parameters. Further, it was observed that the distortion was significant only below $3 \mathrm{~mm}$ thickness because of surface induced stresses due to machining. Further study should be focused on the effect of machining and tool parameters on the distortion of the parts machined.

\section{Acknowledgements}

The authors are thankful to the Head of Department, Osmania University for his constant encouragement and Support for conducting experiments. The authors are also thankful to the reviewers for their valuable inputs in improving quality of the manuscript.

\section{References}

[1] Sridhar, Garimella, and P. Ramesh Babu. "Understanding the challenges in machining thin walled thin floored Avionics components, " International Journal of Applied Science and Engineering Research 2.1: 93-100, 2013.

[2] Stephenson, D. A., Agapiou, J. S., Metal Cutting Theory and Practice, Second Edition, CRC, Boca Raton, FL, 568-9, 2006.
[3] Marusich T. D., D. A. Stephenson, S. Usui, and S. Lankalapalli, "Modeling Capabilities for Part Distortion Management for Machined Components." Third Wave Systems (2009).

[4] Totten, George E., and D. Scott MacKenzie, eds. Handbook of Aluminum: Vol. 1: Physical Metallurgy and Processes. Vol. 1. CRC Press, 2003.

[5] Chatelain, Jean-François, Jean-François Lalonde, and Antoine S Tahan, "Effect of Residual Stresses Embedded within Workpieces on the Distortion of Parts after Machining," International Journal of Mechanics 6: 43-5, 2012.

[6] Cui, Hengbo, Jong-Yun Jung, and Dug-Hee Moon, "The Selection of Machining Parameters to Minimize Deformation caused by Heat," Proceedings of the Fall Conference of Society of Korea Industrial and Systems Engineering, Korea. 2005.

[7] DONG, Hui-yue, and Ying-lin KE, "Study on machining deformation of aircraft monolithic component by FEM and experiment," Chinese Journal of Aeronautics 19.3: 247-254, 2006.

[8] Lalonde, J. F., M. A. Gharghouri, and J. F. Chatelain, "Effect of Residual Stresses on the Distortion of Components after Machining.", NRC-CNBC Annual Report 2007.

[9] Younger, Mandy S., and Kenneth H. Eckelmeyer. "Overcoming residual stresses and machining distortion in the production of aluminium alloy satellite boxes," Sandia Report SAND2007-6811, Sandia National Laboratories, 2007.

[10] Denkena, B., and L. de León, "Machining induced residual stress in wrought aluminium parts, " Proceedings of 2nd International Conference on Distortion Engineering. 2008.

[11] Belgasim, O., and M. H. El-Axir, "Modeling of residual stresses induced in machining aluminum magnesium alloy ( $\mathrm{Al}-3 \mathrm{Mg}), "$ Proceedings of the world congress on engineering, Vol. 2. 2010. 
[12] Garimella Sridhar and P. Ramesh Babu, "Cutting Parameter Optimization for Minimizing Machining Distortion of Thin Wall Thin Floor Avionic Components using Taguchi Technique", International Journal of Mechanical Engineering \& Technology (IJMET).Volume:4,Issue:4,Pages:71-78, 2013.

[13] Keleshian, N., et al., "On the distortion and warpage of 7249 aluminum alloy after quenching and machining," Journal of materials engineering and performance 20.7: 1230-1234, 2011.

[14] Songtao Wang, Zheng Minli, Fan Yihang, and Li Zhe, "Cutting Parameters Optimization in Machining Thin-Walled Characteristics of Aircraft Engine Architecture based on Machining Deformation," Advances in Information Sciences \& Service Sciences 4.10, 2012.
[15] Huang, Xiaoming, et al., "An Experimental Investigation of Residual Stresses in High-Speed End Milling 7050-T7451 Aluminum Alloy," Advances in Mechanical Engineering, 2013.

[16] Huang, Xiaoming, Jie Sun, and Jianfeng Li, "Effect of Initial Residual Stress and Machining-Induced Residual Stress on the Deformation of Aluminium Alloy Plate," Strojniški vestnik-Journal of Mechanical Engineering 61.2: 131-137, 2015.

[17] Ma, K., R. Goetz, and S. K. Srivatsa. "Modeling of residual stress and machining distortion in aerospace components." ASM Handbook 22, 2010. 